\title{
CANA-DE-AÇÚCAR: COMPORTAMENTO DE VARIEDADES EM PIRACICABA, SP (1)
}

\author{
VIRGINIO BOVI $\left({ }^{2,3}\right)$, JOSÉ CIONE $\left({ }^{2}\right)$ \\ e ANTONIO PEREIRA DE CAMARGO $\left({ }^{2,3}\right)$
}

\begin{abstract}
RESUMO
Na Estação Experimental de Piracicaba, do Instituto Agronômico, durante o período 1976-1979, em Latossolo Roxo, foi efetuado experimento a fim de estudar o comportamento das seguintes variedades de cana-de-açúcar: CB41-76, CB36-24, CB40-69, CB47-89, CB47-355, CB53-98, IAC52-179 e Co740, distribuŕdas para o plantio comercial, e IAC60-537, Co1148, CP51-22 e Q76, consideradas promissoras. Os resultados mostraram, comparando-se as produções de açúcar e de cana por área, que CP51.22 e Co740 tiveram o melhor comportamento, seguidas pelas variedades IAC $60-537$, CB $41-76$, CB47-89 e CB5 3-98.
\end{abstract}

Termos de indexação: cana-de-açúcar; comportamento de variedades; teor de açúcar; açúcar por área.

\section{INTRODUÇÃO}

As variedades de cana-de-açúcar cultivadas com finalidade industrial são periodicamente substituídas, por vários motivos, entre eles o declínio de produção, caracterizado pela redução do vigor das plantas, e a diminuição dos rendimentos agricola e industrial (SEGALLA, 1964). Por outro lado, o

\footnotetext{
( $\left.{ }^{1}\right)$ Recebido para publicação em 6 de novembro de 1984. SP.

$\left({ }^{2}\right)$ Estação Experimental de Piracicaba, Instituto Agronômico, Caixa Postal 28, 13100 Campinas,

$\left({ }^{3}\right)$ Com bolsa de suplementação do CNPq.
} 
rápido desenvolvimento dos trabalhos e melhoramento genético da cultura, criando novas variedades com melhores características, tem provocado substituições mais freqüentes.

A substituição de uma variedade em cultivo por outra de melhores qualidades pode, sem despesas adicionais, proporcionar apreciável aumento nos rendimentos agrícola e industrial $\left({ }^{4}\right)$.

$O$ presente trabalho teve por objetivo estudar o comportamento de algumas variedades de cana-de-açúcar em distribuição pela Estação Experimental de Piracicaba e de outras consideradas promissoras.

\section{MATERIAL E MÉTODOS}

O experimento foi conduzido na Estação Experimental de Piracicaba, em Latossolo Roxo, com pH 6,4 (relação solo:água $1: 2,5$ ), matéria orgânica $3,4 \%$, alumínio trocável, traços, cálcio trocável 3,0 e. $\mathrm{mg} / 100 \mathrm{ml}$ de solo, magnésio trocável 1,7 e.mg/100ml de solo, potássio $41 \mu \mathrm{g} / \mathrm{ml}$ de solo e fósforo $2 \mu \mathrm{g} / \mathrm{ml}$ de solo.

A adubação básica consistiu em $250 \mathrm{~kg} /$ ha de sulfato de amônio, sendo $1 / 3$ da dose aplicada no sulco de plantio e o restante, 30 dias após, em cobertura, ao lado das plantas; $400 \mathrm{~kg} / \mathrm{ha}$ de superfosfato simples e $200 \mathrm{~kg} / \mathrm{ha}$ de cloreto de potássio. A adubação de soca e ressoca, em termos de $\mathrm{N}_{\text {e }} \mathrm{K}_{2} \mathrm{O}$, foi de 60 e $120 \mathrm{~kg} /$ ha respectivamente, aplicados em cobertura, na superfície do solo, ao lado das linhas.

Mediante delineamento experimental em blocos ao acaso, com quatro repetições, foram estudadas as seguintes variedades de cana-de-açúcar em distribuição na ocasião: CB41-76, CB36-24, CB40-69, CB47-89, CB47-355, CB53-98, IAC52-179 e Co740, e as promissoras: IAC60-537, Co1148, CP5122 e Q76. Duas dessas variedades figuravam entre as dez mais cultivadas no Estado de São Paulo: a CB41-76 era a principal, ocupando $32,5 \%$, e a CB47355, 2,3\% da área cultivada com cana-de-açúcar (PLANALSUCAR, 1976).

As parcelas experimentais foram constituídas por três linhas de $10 \mathrm{~m}$ de comprimento, espaçadas de $1,40 \mathrm{~m}$. No plantio, realizado em abril de 1976, colmos com doze meses de idade foram cortados dentro dos sulcos, deixando-se dez gemas por metró linear.

Foram feitos três cortes, utilizando-se as três linhas de cada parcela, sendo o primeiro deles em outubro de 1977 e o segundo e o terceiro,

(4) ESPIRONELO, A; ALVAREZ, R.; POMMER, C.V. \& OLIVEIRA, H. Levantamento e diagnóstico da cultura đa cana-de-açúcar. Instituto Agronômico, Campinas, 1980. Mimeo. 
com intervalos de um ano, como normalmente se faz na cultura da cana-deaçúcar.

Por ocasião das colheitas, foram tomados ao acaso dez colmos de cada parcela para as determinações tecnológicas. $O$ açúcar provável por tonelada de cana foi calculado pela fórmula de Winter Carp-Geerligs, modificada por ARCENEAUX (1935), com a eficiência das caldeiras modificadas para $88 \%$, segundo AGUIRRE JUNIOR $\left({ }^{5}\right)$ para melhor adaptação dos cálculos às condições das usinas paulistas. $O$ açúcar provável por área $(t / h a)$ foi calculado através dos dados de produção de cana $(t / h a)$ e do teor de açúcar (kg/t cana).

\section{RESULTADOS E CONCLUSÕES}

No quadro 1 , encontram-se as produções de cana e de açúcar obtidas nos três cortes. As análises estatísticas, realizadas com as produçōes totais dos três cortes, apresentaram diferenças altamente significativas entre as variedades, com respeito às três características estudadas.

QUADRO ! - Produçoes de cana e de açúcar obtidas em experimento de competiçăo de variedađes conduzido na Estaçăo Experimental de Puracicaba

\begin{tabular}{|c|c|c|c|c|c|c|c|c|c|c|c|c|}
\hline \multirow{3}{*}{ Variedades } & \multicolumn{3}{|c|}{ Primeiro corte } & \multicolumn{3}{|c|}{ Segundo corte } & \multicolumn{3}{|c|}{ Terceiro corte } & \multicolumn{3}{|c|}{ Totais } \\
\hline & \multirow{2}{*}{$\frac{\text { Cana }}{\text { t/ha }}$} & \multicolumn{2}{|c|}{ Açúcar } & \multirow{2}{*}{$\frac{\text { Cana }}{\mathrm{t} / \mathrm{ha}}$} & \multicolumn{2}{|c|}{ Açúcar } & \multirow{2}{*}{$\begin{array}{c}\text { Cana } \\
\text { t/ha }\end{array}$} & \multicolumn{2}{|c|}{ Açúcar } & \multirow{2}{*}{$\begin{array}{l}\text { Cana } \\
\text { tha }\end{array}$} & \multicolumn{2}{|c|}{ Açúcar } \\
\hline & & $\mathrm{kg} / \mathrm{t}$ & t/ha & & $\mathrm{kg} / \mathrm{t}$ & $\mathrm{t} / \mathrm{ha}$ & & $\mathrm{kg} / \mathrm{t}$ & $\mathrm{t} / \mathrm{ha}$ & & $\mathrm{kg} / \mathrm{t}$ & $\mathrm{t} / \mathrm{ha}$ \\
\hline Co 740 & 136,15 & 138,33 & 18,82 & 106,07 & 128,76 & 13,65 & 106,22 & 101,65 & 10,79 & $348,44 a b$ & $122,91 \mathrm{a}$ & $43,26 a$ \\
\hline CP51-22 & 144,00 & 131,43 & 18,92 & 105,05 & 125,74 & 13,20 & 104,55 & 98,24 & 10,27 & $356,60 \mathrm{a}$ & $118,47 a b$ & $42,39 a$ \\
\hline LAC60.537 & 116.40 & 127.56 & 14,84 & 105.33 & 127,45 & 13,42 & 110,91 & 93,80 & 10,40 & $332,64 b c$ & $116,27 \mathrm{ab}$ & $38,66 \mathrm{bc}$ \\
\hline CB41.76 & 132,99 & 128,20 & 17.04 & 90,87 & 117,21 & 10,65 & 106,17 & 99,06 & 10,50 & $330,03 b c$ & $114,82 a b$ & $38,19 b c$ \\
\hline CB47.89 & 126,74 & 123,20 & 15,61 & 106,41 & 119,41 & 12,71 & 98,74 & 97,06 & 9,58 & $331,89 \mathrm{bc}$ & $113,22 \mathrm{ab}$ & $37,90 \mathrm{bc}$ \\
\hline CB53-98 & 118,71 & 123,20 & 14,62 & 100,21 & 123,21 & 12,39 & 107,09 & 92,11 & 9,86 & $326,01 \mathrm{c}$ & $112,84 b$ & $36,87 \mathrm{bc}$ \\
\hline CB40-69 & 115,24 & 128.72 & 14.83 & 97,61 & 119,49 & 11,66 & 103,40 & 95,12 & 9,83 & $316,25 c d$ & $114,44 a b$ & $36,32 \mathrm{~cd}$ \\
\hline CB36-24 & 129,96 & 115,48 & 15,00 & 93,38 & 120,21 & 11,23 & 91,91 & 90,40 & 8,30 & $315,25 \mathrm{~cd}$ & $108,69 b$ & 34,53de \\
\hline Q76 & 114,13 & 133,14 & 15,15 & 81,99 & 125,57 & 10,29 & 88,25 & 96,89 & 8,55 & $284,37 \mathrm{e}$ & $118,53 a b$ & $33,99 \mathrm{e}$ \\
\hline Co 1148 & 106,95 & 127,13 & 13,59 & 88,35 & 123,20 & 10,88 & 101,09 & 92,50 & 9,35 & $296,39 \mathrm{de}$ & $114,27 a b$ & $33,82 \mathrm{e}$ \\
\hline CB47.355 & 95,60 & 119,54 & 11.42 & 84,80 & 119,70 & 10,15 & 99,33 & 94,50 & 9,38 & $279,73 \mathrm{e}$ & $111,24 b$ & $30,85 \mathrm{f}$ \\
\hline IAC52-179 & 92,80 & 123,32 & 11,44 & 75,60 & 128,80 & 9,74 & 84,18 & 95,73 & 8,05 & $252,58 \mathrm{f}$ & $115,95 \mathrm{ab}$ & $29,23 \mathrm{f}$ \\
\hline \multirow{3}{*}{\multicolumn{4}{|c|}{$\begin{array}{l}\text { F } \\
\text { D.M.S. (Tukey 5\%) } \\
\text { CV }(\%)\end{array}$}} & & & & & & & $12,99 * *$ & $3,30 * *$ & $6,28 * *$ \\
\hline & & & & & & & & & & 20,91 & 9,88 & 1,94 \\
\hline & & & & & & & & & & 8,07 & 3,45 & 11,62 \\
\hline
\end{tabular}

As letras năo comuns expressam diferença significativa (Tukey 5\%). ** Significativo a $1 \%$.

(5) AGUIRRE JUNIOR, J.M. Relatório da Seção de Cana-de-Açúcar para o ano de 1940. Instituto Agro nômico. (Não publicado.) 
Com referência à produção de cana, destacou-se a CP51-22, que se diferenciou das demais, com exceção da Co740. Esta não se diferenciou das variedades IAC60-537, CB47-89, CB41-76 e CB53-98, constituindo as quatro um grupo colocado em segundo lugar, quanto à produtividade.

Em relação ao açúcar obtido por tonelada de cana (teor de açúcar), destacou-se a Co740, que, entretanto, foi significativamente superior apenas à CB36-24, CB47-355 e CB53-98.

Quando se considera a produção de açúcar por hectare, tiveram destaque as variedades Co740 e CP51-22, estatisticamente diferentes das demais, secundadas pelas variedades IAC60-537, CB41-76, CB47-89 e CB53-98, num mesmo grupo.

Esses resultados não concordam com aqueles obtidos em dois experimentos também conduzidos em Piracicaba, no período 1970-1973 (SEGALLA et alii, 1980). Em um, na Usina Piracicaba, a CP51-22 não se diferenciou signifícativamente da CB41-76, considerada como testemunha, enquanto no outro, efetuado na Estação Experimental, foi a Co740 que não diferiu significativamente da CB41-76, nas três características estudadas. Entretanto, em relação às variedades Co740 e CB47-89, concordam com os resultados obtidos em experimento conduzido no período 1976-1979 (BOVI et alli, 1983), quando elas não se diferenciaram significativamente na produção de cana, enquanto a CB41-76, não apresentando bom desempenho nesse experimento, diferenciou-se dessas duas variedades, tanto na produção de cana como de açúcar por área.

Em vista dos resultados obtidos e considerando a importância da produção de açúcar por área, as variedades em distribuição Co 740, CB41-76, CB53-98 e CB47-89 apresentaram bom desempenho, com destaque da primeira, que, entretanto, revelou grande suscetibilidade ao mosaico. Entre as promissoras, as variedades CP51-22 e IAC60-537 revelaram bom comportamento, nas três características estudadas, destacando-se a primeira.

\section{SUMMARY}

PERFORMANCE OF SUGARCANE VARIETIES IN PIRACICABA, STATE OF SĀO PAULO, BRAZIL

An experiment was carried out during the period 1976 to 1979 , in Latosolic B 'terra roxa', at Instituto Agronômico Experimental Station, in Piracicaba, State of São Paulo, Brazil, to evaluate the performance of the following sugarcane varieties: CB41-76, CB36-24, CB40-69, CB47-89, CB47-355, CB53-98, IAC52-179, Co740, IAC60-537, Co1148, CP51-22 and Q76. The results showed that CP51-22 and Co740 had the best performance, followed by the varieties IAC60-537, CB41-76, CB47-89 and CB53-98 in terms of cane and sugar yields ( $t / h a)$.

Index terms: sugarcane; performance of varieties; sugar content; sugar yield. 


\section{REFERÊNCIAS BIBLIOGRÁFICAS}

ARCENEAUX, G. A simplifield method of theorical sugar yield calculations. International Sugar Journal, 38:264-265, 1935.

ÁREAS com canaviais no Brasil. PLANALSUCAR. Relatório Anual, Piracicaba, 1976. p.6-7.

BOVI, V.; CIONE, J. \& PEREIRA, A.P. Comportamento de variedades de cana-de-açúcar no plantio de setembro-outubro na região de Piracicaba (SP). Bragantia, Campinas, 42:47-50, 1983.

SEGALLA, A.L. Botânica, melhoramento e variedades. In: MALAVOLTA, E. Cultura e adubação da cana-de-açúcar. São Paulo, Instituto Brasileiro de Potassa, 1964. p. 61-96.

; OLIVEIRA, H.; ESPIRONELO, A. \& IGUE, T. Experimentos regionais de cana-de-açúcar realizados no período de 1970 a 1973. Bragantia, Campinas, 39:115-135, 1980. 